\title{
Psychophysical methodology: VI. Random method of limits
}

\author{
ROBERT M. HERRICK \\ L.S. Naval Air Development Center, IVarminster, Pennsyliania 18974
}

\begin{abstract}
A description is given of a psychophysical method that incorporates the beneficial features of the method of limits (ML) and the method of constant stimuli (MCS). Successive stimuli in a series are presented in random order. The data are treated either as data of a ML experiment or as data of a MCS experiment. The mean threshold is the same as that obtained in the ML or in the MCS. For a given number of judgments. the accuracy of the mean threshold is about the same as the accuracy obtained with the ML. The method eliminates knowledge of the order of the stimuli. and allows evaluation of time-correlated fluctuations in sensitivity.
\end{abstract}

An analysis will be given of a method that integrates the beneficial features of the method of limits (ML) with those of the method of constant stimuli (MCS). The method may be considered a variation of either the ML or the MCS. The data collection procedure is not new. Guilford (1954, p. 113) credits Kraepelin with the invention of the method. Among others, Holt (1904), Titchener (1905), and Urban (1907, 1908) have discussed the method. The method has been referred to as the method of irregular variation and also as the haphazard method. I will call it the random method of limits (RML) to indicate its relationship to the ML while emphasizing that the stimuli are presented in a random order.

Specific rules for data collection with the RML will be described. Using these rules, a quantitative analysis of the RML will be given. This analysis will provide, for any psychometric function, the expected threshold distributions, as well as summary statistical measures of the threshold..distributions. Then, on the assumption that the psychometric function is a cumulative normal curve, numerical constants will be derived to describe the RML threshold distributions. The RML will also be related to the ML and to the MCS.

\section{DESCRIPTION OF METHOD}

\section{Data Collection Rules}

Select six equally spaced stimuli. $\mathrm{S}_{0}, \mathrm{~S}_{1}, \mathrm{~S}_{2}, \mathrm{~S}_{3}, \mathrm{~S}_{4}$. $S_{5}$, such that the probability of a "ves" response is at zero $\left(p_{0}=.00\right)$ for the weakest stimulus, $S_{0}$, and at certainty $\left(p_{s}=1.00\right)$ for the strongest stimulus, $S_{s}$ (see Table 1). Present the six stimuli in a random order and record the O's response, "yes" or "no," to each stimulus. Repeat this procedure several times. If more or less than six stimuli are used, follow a similar procedure.

\section{Data Treatment}

If data are collected for, say, 10 or more series of judgments, across each row of data determine the proportion of "yes" responses and thereby obtain estimates of $p_{0}, p_{1}, p_{2}, p_{3}, p_{4}$, and $p_{5}$ (see Table 1 ).

Table 1

Examples of Series of Judgments and Computation of Thresholds in the Random Method of Limits

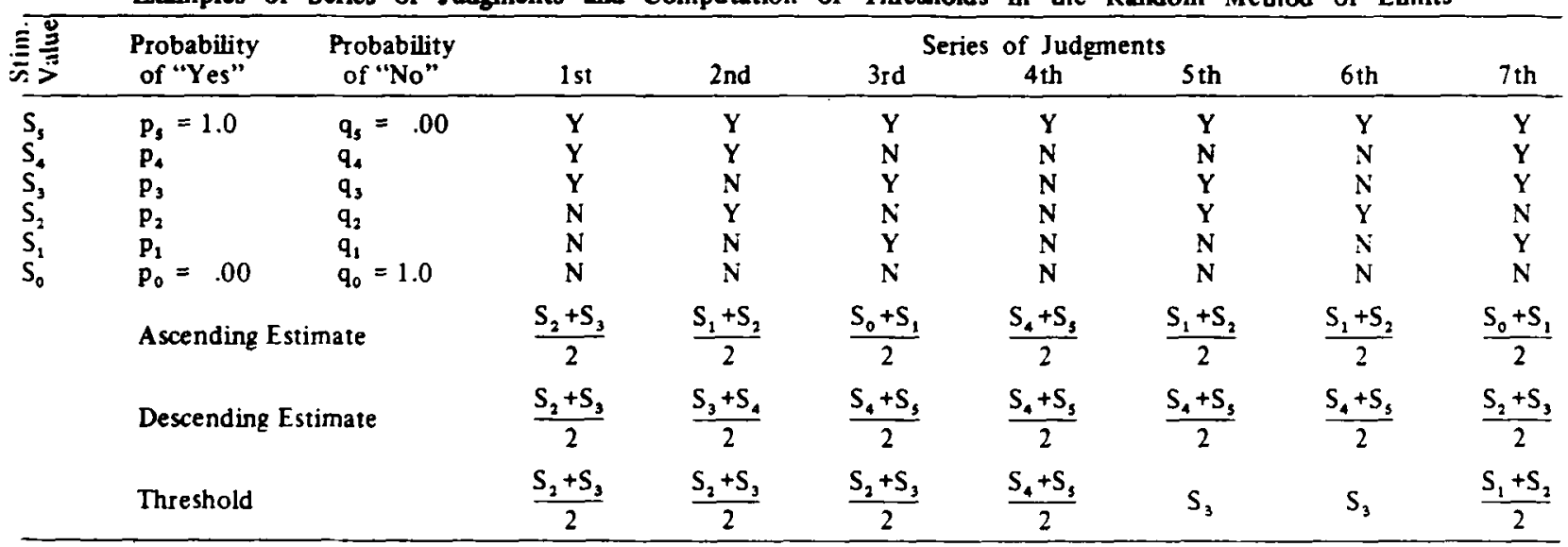

. Vote-In each series, the six stimuli are presented in random order. $Y=$ "Yes,".V $=" N_{0}: " p_{5}>p_{4} \ldots>p_{0}$. Stimuli $S_{0}, S_{1}, \ldots . S_{\text {, }}$ are equally spaced. 
Table 2

Relative Frequencies of Thresholds With Six Stimuli and Two Psychophysical Methods

\begin{tabular}{ccc}
\hline & \multicolumn{1}{c}{ Relative Frequency of Threshold } \\
\cline { 2 - 3 } Threshold & Random Method of Limits (RML) & Combined Method of Limits (CML) \\
\hline$\left(S_{4}+S_{5}\right) / 2$ & $q_{1} q_{2} q_{3} q_{4}$ & {$\left[q_{1} q_{2} q_{3} q_{4}+q_{4}\right] / 2$} \\
$\left(S_{3}+S_{4}\right) / 2$ & $q_{1} q_{2}\left[p_{3} q_{4}+q_{3} p_{4}\right]$ & {$\left[q_{1} q_{2} q_{3} p_{4}+p_{4} q_{3}\right] / 2$} \\
$S_{3}$ & $q_{1} p_{2} q_{4}$ & 0 \\
$\left(S_{2}+S_{3}\right) / 2$ & $p_{1} q_{4}+q_{1} p_{4}\left[p_{2} q_{3}+q_{2} p_{3}\right]$ & {$\left[q_{1} q_{2} p_{3}+p_{4} p_{3} q_{2}\right] / 2$} \\
$S_{2}$ & $p_{2} q_{3} p_{4}$ & 0 \\
$\left(S_{1}+S_{2}\right) / 2$ & $p_{3} p_{4}\left[p_{1} q_{2}+q_{1} p_{2}\right]$ & {$\left[q_{1} p_{2}+p_{4} p_{3} p_{2} q_{1}\right] / 2$} \\
$\left(S_{0}+S_{1}\right) / 2$ & $p_{1} p_{2} p_{3} p_{4}$ & {$\left[p_{1}+p_{4} p_{3} p_{2} p_{1}\right] / 2$} \\
& $\Sigma=1.00$ & $\Sigma=1.00$ \\
\hline
\end{tabular}

Plot the estimates of the $p$ values vs the stimulus values and determine, by methods used with the method of constant stimuli (MCS), the mean and standard deviation of the distribution.

As an alternative to the treatment just described, do the following. Treat each series of six judgments both as an ascending series and as a descending series of the method of limits, thereby obtaining upper and lower estimates $^{1}$ (see Table 1). The mean of these two estimates is the threshold. The distribution of thresholds obtained in this way will have a mean $M_{R}$ and a standard deviation $\sigma_{\mathrm{R}}$.

\section{ANALYSIS OF METHOD}

\section{Derivation of Threshold Distribution}

In Table 1, the first series of judgments are no, no, no, yes, yes, yes, for stimuli $S_{0}, S_{1}, S_{2}, S_{3}, S_{4}, S_{5}$, respectively. Assuming independence, the probability' of obtaining this particular series of judgments is equal to the probability of obtaining a "no" at $S_{0}$ times the probability of obtaining a "no" at $S_{1}$ times the probability of obtaining a "no" at $S_{2}$ times the probability of obtaining a "yes" at $S_{3}$, etc. In short, the probability of obtaining the first series is $q_{0} q_{1} q_{2} p_{3} p_{4} p_{5}$. Since $q_{0}=1.00$ and $p_{5}=1.00$, $q_{0} q_{1} q_{2} p_{3} p_{4} p_{5}$ may be simplified to $q_{1} q_{2} p_{3} p_{4}$. The probability of obtaining the second series given in Table 1 is $q_{1} p_{2} q_{3} p_{4}$.

Table 1 shows seven different series of judgments. The number of different series possible depends upon the number of stimuli used to cover the range from $p=.00$ to $p=1.00$. Assuming the $p$ values associated with the highest and lowest stimuli are 1.00 and .00 , respectively, the lowest stimulus $\left(S_{0}\right)$ will always yield a "no" judgment and the highest will alway's yield a "yes" judgment. Each of the other stimuli. however, may evoke either a "yes" or a "no." Thus, with a total of six stimuli. as in Table 1, four stimuli may evoke either a "yes" or a "no." so the number of different series possible is $2^{4}$, or 16 . In general, the number of different series possible is $2^{n-2}$. where $n$ is the number of stimuli. including the highest and lowest stimuli where the $p$ values are, respectively. 1.00 and 0.00 .

With the RML. it is possible to obtain a threshold midway between any two adjacent stimuli: for example, at $\left(S_{0}+S_{1}\right) / 2$, at $\left(S_{1}+S_{2}\right) / 2$, etc. Thus, $(n-1)$ different thresholds are obtainable in this manner. It is also possible to obtain a threshold at any stimulus except the two lowest and the two highest: with six stimuli (Table 1), thresholds of $S_{2}$ and $S_{3}$ are possible, but thresholds of $S_{0}, S_{1}, S_{4}$, or $S_{5}$ are not. Thus, $(n-4)$ thresholds are obtainable in this manner. In short, the total number of different thresholds possible is $(n-1)+(n-4)$, or $2 n-5$.

Since $n$ stimuli yield $2^{n-2}$ different series of judgments but only $2 \mathrm{n}-5$ different thresholds, different series of judgments yield the same threshold. The first, second, and third series in Table 1, for example, all give a threshold of $\left(S_{2}+S_{3}\right) / 2$. All series yielding the same threshold may be grouped together to obtain the probability of obtaining a particular threshold. For example, in Table 1, the fifth and sixth series yield the same threshold, $S_{3}$. No other combination of judgments yields a threshold of $S_{3}$. The probability of obtaining the fifth series is $q_{1} p_{2} p_{3} q_{4}$, and the probability of obtaining the sixth series is $q_{1} p_{2} q_{3} q_{4}$. Thus. the probability of obtaining threshold $S_{3}$ is $q_{1} p_{2} p_{3} q_{4}+q_{1} p_{2} q_{3} q_{4}$, which may be simplified to $q_{1} p_{2} q_{4}$, since $p_{3}+q_{3}=1.00$.

With a large number of series, the probability of obtaining a particular threshold equals the proportion, or relative frequency, of thresholds of that value. Thus, of all the thresholds, the proportion that are $S_{3}$ is $q_{1} p_{2} q_{4}$. Table 2 indicates, for six stimuli, the relative frequency expected for each of the seven RML thresholds. and thus represents the distribution of thresholds. Similar frequency distributions may be derived for any number of stimuli. For comparison, the relative frequency of thresholds expected with the combined method of limits (CML) is included in Table 2 (see below).

The mean of the RML distribution of thresholds of Table 2. $M_{R}$, is given by:

$$
\begin{aligned}
M_{R}= & {\left[\left(S_{0}+S_{1}\right) / 2\right] p_{1} p_{2} p_{3} p_{4} } \\
& +\left[\left(S_{1}+S_{2}\right) / 2\right] p_{3} p_{4}\left(p_{1} q_{2}+q_{1} p_{2}\right) \\
& +\ldots+\left[\left(S_{4}+S_{5}\right) / 2\right] q_{1} q_{2} q_{3} q_{4}
\end{aligned}
$$


Call the step size c, i.e., $S_{5}-S_{4}=S_{4}-S_{3}=\ldots=$ $S_{1}-S_{0}=c$. Then, $\left(S_{0}+S_{1}\right) / 2=S_{0}+.5 c ;\left(S_{1}+S_{2}\right) / 2=$ $\mathrm{S}_{0}+1.5 \mathrm{c}: \mathrm{S}_{2}=\mathrm{S}_{0}+2 \mathrm{c} ; \ldots ;\left(\mathrm{S}_{4}+\mathrm{S}_{5}\right) / 2=\mathrm{S}_{0}+4.5 \mathrm{c}$. Substituting $\left(\mathrm{S}_{0}+.5 \mathrm{c}\right)$ for $\left(\mathrm{S}_{0}+\mathrm{S}_{1}\right) / 2$ and making similar substitutions in Eq. 1, and simplifying, gives:

$$
\begin{aligned}
M_{R}= & S_{0}+c\left[0.5 p_{1} p_{2} p_{3} p_{4}+1.5 p_{3} p_{4}\left(p_{1} q_{2}+q_{1} p_{2}\right)\right. \\
& \left.+\ldots+4.5 q_{1} q_{2} q_{3} q_{4}\right] .
\end{aligned}
$$

The variance of the RML distribution of thresholds of Table $2, \sigma_{\mathrm{R}}^{2}$, is given by:

$$
\begin{aligned}
\sigma_{R}^{2}= & {\left[M_{R}-\left(S_{0}+.5 c\right)\right]^{2} p_{1} p_{2} p_{3} p_{4} } \\
& +\left[M_{R}-\left(S_{0}+1.5 c\right)\right]^{2} p_{3} p_{4}\left(p_{1} q_{2}+q_{1} p_{2}\right) \\
& +\ldots+\left[M_{R}-\left(S_{0}+4.5 c\right)\right]^{2} q_{1} q_{2} q_{3} q_{4} .
\end{aligned}
$$

\section{PHI-GAMMA HYPOTHESIS}

The RML threshold distribution of Table 2 with its associated summary statistics of Eqs. 2 and 3 describe the expected results using six stimuli covering the range from $p=.00$ to $p=1.00$, and following the data collection and data treatment rules of the RML. In the derivation, the first and the last $p$ values were taken as .00 and 1.00 , but the others were assigned no specific values. Thus, the derivation given above refers to a general case.

Typically, the researcher knows or assumes how the $p$ values increase as stimulus intensity increases. The most common assumption is that the $\mathrm{p}$ values are described by a cumulative normal curve (phi-gamma hypothesis),

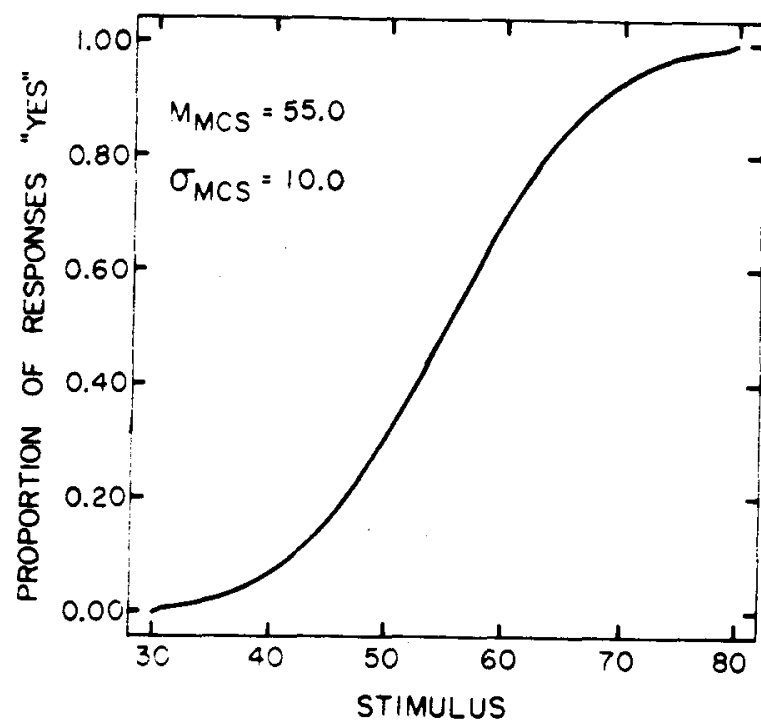

Fig. 1. Psychometric function in the shape of a cumulative normal distribution (phi-gamma hypothesis). The function is considered to terminate at 2.5 standard deviations above and below the mean, i.e.. at 30 and 80 .

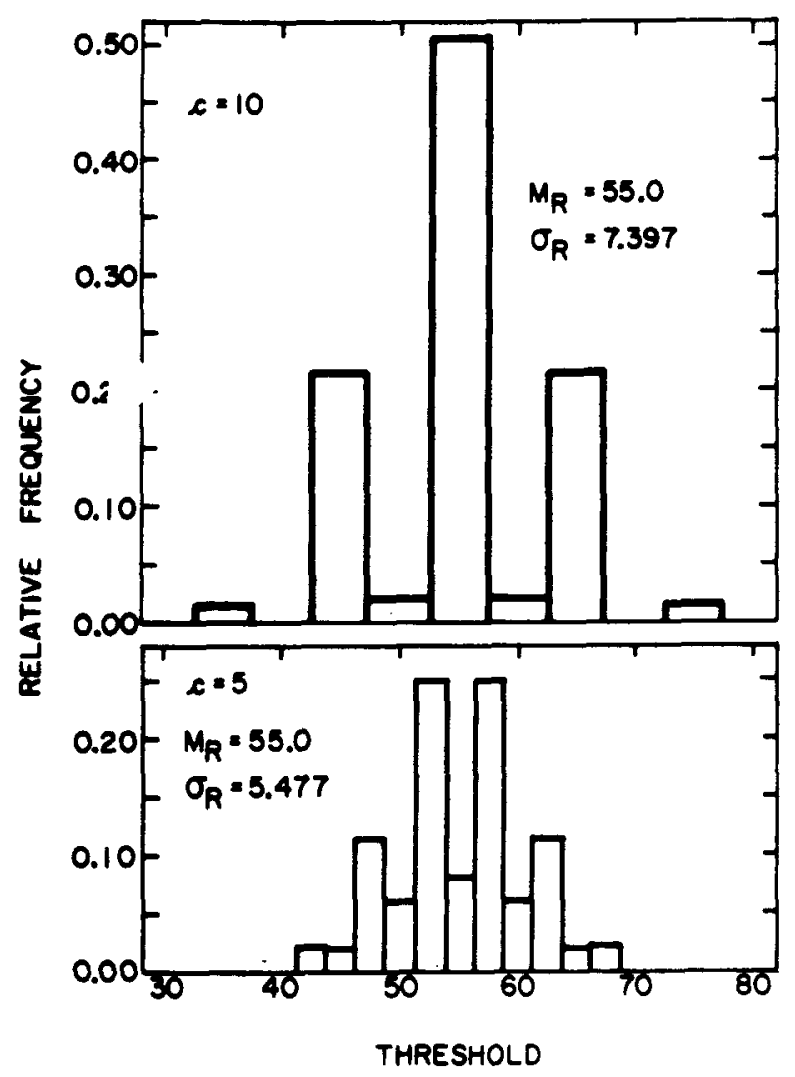

Fig. 2. Two hypothetical threshold distributions of the random method of limits derived from the function of Fig. 1. For the upper panel, the step size $c=\sigma_{\text {MCS }}$; for the lower panel, the step size $c=0.5 \sigma_{\mathrm{MCS}}$. In both cases, the RML stimuli extend from 30 to 80 .

illustrated by a numerical example in Fig. $1 .{ }^{2}$ By assuming a function relating $\mathrm{p}$ and stimulus intensity, quantitative relationships between that function and RML threshold distributions may be derived. ${ }^{3.4}$ For example, if the relationship between the $p$ values and the stimuli are those of Fig. 1, a RML experiment with six stimuli, $30,40,50,60,70$, and 80 , ideally would yield the threshold distribution in the upper panel of Fig. 2. With 11 stimuli, $30,35,40,45, \ldots, 80$, the threshold distribution of the lower panel of Fig. 2 would result. (The process may, of course, be reversed. That is, given either RML distribution of Fig. 2, the function of Fig. 1 can be derived.)

In Appendix A, derivations are given to relate the phi-gamma hypothesis and the RML threshold distributions. The key relations derived are as follows. The mean of the phi-gamma function, $\mathrm{M}_{\mathrm{MCs}}$, is related to the mean of the RML threshold distribution, $\mathrm{M}_{\mathrm{R}}$, to a close approximation, ${ }^{5}$ by

$$
\mathrm{M}_{\mathrm{R}}=\mathrm{M}_{\mathrm{M} \text { cs }} \text {. }
$$

The standard deviation of the phi-gamma function is $\sigma_{\text {Mcs }}$. To a close approximation, the relation between 


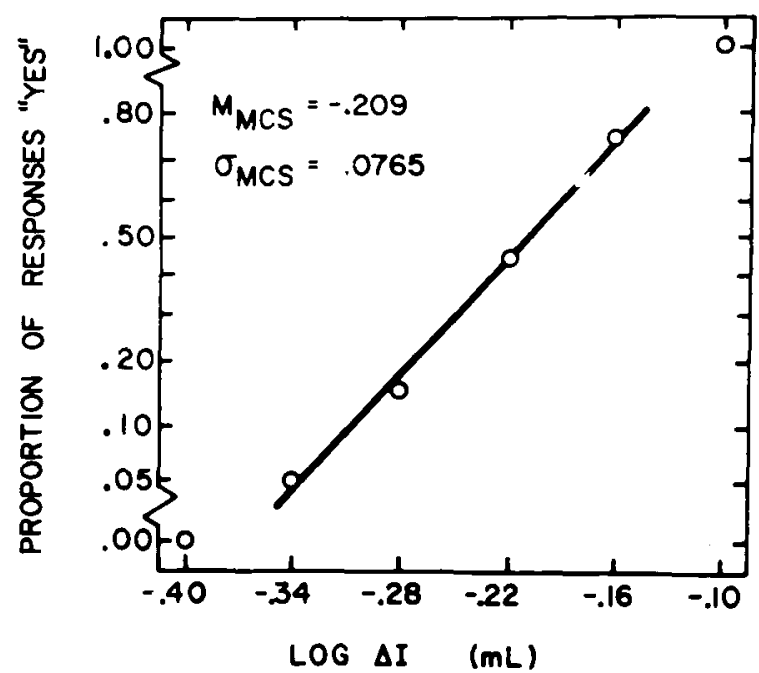

Fig. 3. RML data plotted as a psychometric function. O A.L., Session 1.

the standard deviation of a RML threshold distribution, $\sigma_{\mathrm{R}}$, and step size, $\mathrm{c}$, is described by

$$
\sigma_{\mathrm{R}}^{\prime}=.3188+.4892 c^{\prime}-.0602 c^{\prime 2} .
$$

where $\sigma_{\mathrm{R}}$ and $c$ are given in units of $\sigma_{\mathrm{MCS}}$; i.e., $\sigma_{\mathbf{R}}^{\prime}=$ $\sigma_{\mathrm{R}} / \sigma_{\mathrm{MCs}}$ and $\mathrm{c}^{\prime}=\mathrm{c} / \sigma_{\mathrm{M} c s}$.

The terms $\sigma_{\mathrm{MCS}}: \sigma_{\mathrm{R}}$, and $\mathrm{c}$ are related by

$\sigma_{\mathrm{MCS}}=\frac{\left(\sigma_{\mathrm{R}}-.4892 \mathrm{c}\right)+\sqrt{\left(\sigma_{\mathrm{R}}-.4892 \mathrm{c}\right)^{2}+.0768 \mathrm{c}^{2}}}{.6376}$.

Equations 4.6 hold when the RML step size. c. is between $.5 \sigma_{\mathrm{MCS}}$ and $2.0 \sigma_{\mathrm{MCs}}$, i.e., when $0.5 \leqslant c^{\prime} \leqslant$ 2.0 .

For step sizes from $c^{\prime}=0.5$ to $c^{\prime}=2.0$, the standard error of $M_{R}$ is approximately described by

$$
\mathrm{SE}_{\mathrm{MI}_{\mathrm{R}}}=2.05 \sigma_{\mathrm{MCS}} / \mathrm{J}^{1 / 2}
$$

where $J$ is the number of "yes" and "no" judgments (see Appendix B), and $\sigma_{\mathrm{M} \text { cs }}$ is estimated from Eq. 6.

\section{COMPARISONS OF THE RML WITH OTHER PSYCHOPHYSICAL METHODS}

\section{Combined Method of Limits (CML)}

Assuming the phi-gamma hypothesis, analysis of the method of limits, similar to the present analysis, has been performed (Herrick, 1970a, b. 1972a). The combined method of limits (CML) pools thresholds from the ascending series with an equal number of thresholds from the descending series. The threshold distribution for the CML with six stimuli is given in Table 2 . In the
CML. the mean, standard deviation, and the standard error of the mean threshold are termed $\mathrm{M}_{\mathrm{C}}, \sigma_{\mathrm{C}}$, and

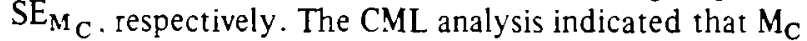
$=\mathrm{M}_{\mathrm{M} \text { cs }}$. Therefore. by Eq. $4, \mathrm{M}_{\mathrm{R}}=\mathrm{M}_{\mathrm{C}}=\mathrm{M}_{\mathrm{Mcs}}$.

In the CML, $\sigma_{\mathrm{C}}$ varies with step size, and at all step sizes when $0.5 \leqslant \mathrm{c}^{\prime} \leqslant 2.0, \sigma_{\mathrm{C}}>\sigma_{\mathrm{R}}$. A comparison of the standard errors of $M_{C}$ and $M_{R}$ indicates that the standard error of $\mathrm{M}_{\mathbf{C}}$ is larger than the standard error of $\mathrm{M}_{\mathrm{R}}$ at $c^{\prime}=0.5$. At $c^{\prime}$ values between 1.0 and 2.0, however, the $\mathrm{SE}_{\mathrm{M}_{\mathrm{C}}}=1.87 \sigma_{\mathrm{MCS}} / \mathrm{J}^{1 / 2}$, and is therefore about $10 \%$ smaller than the $\mathrm{SE}_{\mathrm{M}_{\mathrm{R}}}$ (see Eq. 7). In short, for any given number of judgments, the RML and the CML yield the same mean threshold, with roughly the same accuracy.

Besides the statistical comparison of the RML and the CML, other considerations should apply in comparing the two methods. Compared with the CML, in the RML: (a) O has no information on the order of the stimuli: (b) within every series of six or so judgments, 0 is presented with stimuli at both extremes of the stimulus range, and this should help him to maintain his criterion for a "yes" or a "no": and (c) the standard error of the mean is approximately constant for all step sizes between $c^{\prime}=0.5$ and $c^{\prime}=2.0$, so the selection of step size is somewhat less critical than it is in the CML.

\section{Method of Constant Stimuli (MCS)}

Compared with the MCS, the RML has three advantages: (a) Within every 6 judgments or so, $O$ is presented with stimuli at both extremes of the stimulus range: (b) an estimate of the mean threshold may be obtained with relatively few, say 12, judgments: and (c) time-correlated fluctuations in sensitivity, related to uncontrolled variables, such as fatigue. or related to experimental variables, such as drugs, may be revealed by the examination of successive RML thresholds.

\section{EXAMPLE OF AN RML EXPERIMENT}

\section{Procedure}

The RIIL was used to collect data in a brightriess discrimination experiment. Monocularly. an O centrally fivated a continuously exposed. $11.5-\mathrm{mL}$ adapting field of white light in the form of a disk. $1 \mathrm{deg} 7 \mathrm{~min}$ of visual angle in diam. at an accommodative distance of $57 \mathrm{~cm}$. The adapting field was surrounded by darkness. On command. a $20-\mathrm{msec}$ flash of white light (the $\Delta I$ light) was added to the whole adapting field. and the O signaled "yes" if he detected the flash.

With O A.L.. six log $د$ I luminances differing by 0.06 were used. i.e.. $c=0.06$. With O J.D. six $\log \Delta$ I luminances were used. with $c=0.12$. With each $O$. data were collected in two sessions. In each session. 20 thresholds were obtained by the RML.

\section{Results}

For Session 1 of O A.L.. the data. summarized as the proportion of "yes" responses on a cumulative normal scale. are given in Fig. 3. The line of Fig. 3 is a 
least-squares fit to the four middlemost points. and the mean and standard deviation were derived from the equation for that line. The Session 1 data of O A.L. are also summarized in a RML threshold distribution in Fig. 4. By. Eqs. 4 and 6. estimates of $\mathbf{M}_{\mathrm{MCs}}$ and $\sigma_{\mathrm{MCS}}$ were calculated from the $\mathbf{M}_{\mathbf{R}} \cdot \mathbf{s}_{\mathbf{R}}$. and $c$ values of Fig. 4 . and they are given in the first row of Table 3 . The order of occurrence of the $20 \mathrm{RML}$ thresholds for each session of 0 A.L. are presented in Fig. 5. In Table 3. the results for all four sessions are summarized.

Two recent reports (Herrick, 1972b: Herrick \& Thiesen, 1972) give additional examples of data collected with the RML.

\section{APPENDIX A}

\section{Derivation of Relations Between the Phi-Gamma Hypothesis and the Random Method of Limits} Threshold Distributions

In a RML experiment, three related variables determine the threshold distribution. These are the step size. $c$, the number of stimuli, $n$, and the weakest stimulus. $S_{0}$. Figure 2 illustrates two cases in which the same $S_{0}$, namely 30 , was used with different step sizes, 5 and 10 , and with different numbers of stimuli, 6 and 11 . Both of the R.ML distributions of Fig. 2 were derived from the psychometric function of Fig. 1.

The terms used in a RML experiment may be designated by the mean and the standard deviation of the phi-gamma hypothesis. $\mathrm{M}_{\mathrm{MCs}}$ and $\sigma_{\mathrm{M}} \mathrm{Cs}$. Thus, with $\mathrm{M}_{\mathrm{MCS}}=55$ and $\sigma_{\mathrm{MCS}}=10$, an $\mathrm{S}_{0}$ of 30 may be referred to as ( $\left.\mathbf{M}_{\mathbf{M C S}}-2.5 \sigma_{\mathrm{MCS}}\right)$. Also, the step size, $c$, and the standard deviation, $\sigma_{\mathrm{R}}$, may be specified in units of $\sigma_{\mathrm{MCs}}$, and when so described they will carry a prime: $c / \sigma_{M C S}=c^{\prime} ; \sigma_{R} / \sigma_{M C S}=\sigma_{R}^{\prime}$. The experiment represented in the lower panel of $F$ ig. 2 could be described as one with $\mathrm{S}_{0}=\left(\mathrm{M}_{\mathrm{MCS}}-2.5 \sigma_{\mathrm{MCS}}\right)$ and $c^{\prime}=0.5$, and the results could be given as $M_{R}=M_{M c S}$ and $\sigma_{\mathbf{R}}^{\prime}=.5477$.

Foṛ step size $c^{\prime}=1.0, \mathrm{M}_{\mathbf{R}}$ and $\sigma_{\mathbf{R}}$ were calculated for

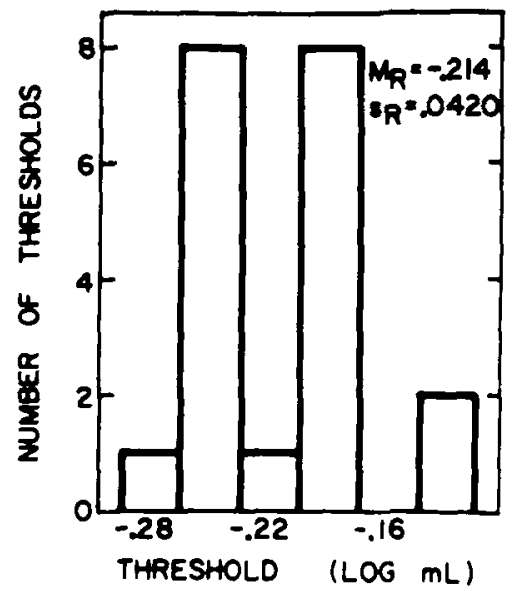

Fig. 4. Random method of limits threshold distribution. 0 A.L.. Session 1.
Table 3

Statistics of Four Brightness Discrimination Experiments With the Random Method of Limits

\begin{tabular}{|c|c|c|c|c|c|c|c|}
\hline \multirow[b]{3}{*}{0} & \multirow{3}{*}{$\begin{array}{l}\text { Ses- } \\
\text { sion }\end{array}$} & \multirow{2}{*}{\multicolumn{2}{|c|}{$\begin{array}{c}\text { Statistics } \\
\text { of RML } \\
\text { Threshold } \\
\text { Distribution } \\
\end{array}$}} & \multicolumn{4}{|c|}{$\begin{array}{c}\text { Statistics of } \\
\text { Psychometric Function }\end{array}$} \\
\hline & & & & \multicolumn{2}{|c|}{$\begin{array}{l}\text { By Equations } \\
\text { (4) and (6) }\end{array}$} & \multicolumn{2}{|c|}{$\begin{array}{l}\text { By Least- } \\
\text { Squares Fit }\end{array}$} \\
\hline & & $\mathbf{M}_{\mathbf{R}}$ & $s_{R}$ & $\mathbf{M}_{\mathrm{MCS}}$ & ${ }^{\sigma} \mathrm{MCS}$ & $\mathrm{M}_{\mathrm{MCS}}$ & $\sigma_{\mathrm{MCS}}$ \\
\hline A.L. & $\begin{array}{l}1 \\
2\end{array}$ & $\begin{array}{l}-.214 \\
-.270\end{array}$ & $\begin{array}{l}.0420 \\
.0518\end{array}$ & $\begin{array}{l}-.214 \\
-.270\end{array}$ & $\begin{array}{l}.0526 \\
.0790\end{array}$ & $\begin{array}{l}-.209 \\
-.273\end{array}$ & $\begin{array}{l}.0765 \\
.0734\end{array}$ \\
\hline D. & $\begin{array}{l}1 \\
2\end{array}$ & $\begin{array}{l}-.364 \\
-.358\end{array}$ & $\begin{array}{l}.0835 \\
.0873\end{array}$ & $\begin{array}{l}-.364 \\
-.358\end{array}$ & $\begin{array}{l}.1039 \\
.1136\end{array}$ & $\begin{array}{l}-.364 \\
-.351\end{array}$ & $\begin{array}{l}.1132 \\
.1404\end{array}$ \\
\hline
\end{tabular}

Vote-All statistics in units of log millilamberts.

different $S_{0}$ values, with $S_{0}$ varying from $\left(\mathrm{M}_{\mathrm{MCS}}-2.5 \sigma_{\mathrm{MCS}}\right)$ to $\left(\mathrm{M}_{\mathrm{MCS}}-4.5 \sigma_{\mathrm{MCS}}\right)$. For any $S_{0}$, the highest $S$ value used was the first one in the series with an associated $p=1.00$. (As mentioned earlier, $\mathrm{p}$ values at and above 2.5 standard deviations above the mean were taken as 1.00.) For example, with $\mathrm{S}_{0}=24$, the stimuli were $24,34,44,54,64,74$, and 84 ; the stimuli range from 24 to 84 , or from $\left(\mathrm{M}_{\mathrm{MCS}}-3.1 \sigma_{\mathrm{MCS}}\right)$ to $\left(\mathrm{M}_{\mathrm{MCS}}+2.9 \sigma_{\mathrm{MCS}}\right)$.

The results of the calculations for $c^{\prime}=1.0$ are given in Figs. 6 and 7. Figure 6 indicates that $M_{R}$ differs from $M_{\mathrm{MCs}}$ by very little, less than $.007 \sigma_{\mathrm{MCs}}$. for different $S_{0}$ values. (The experiment of the upper panel of $F$ ig. 2 is represented by the last point on the right in Fig. 6.) Figure 7 indicates that $\sigma_{\mathbf{R}}$ is relatively constant for different $S_{0}$ values, although it is considerably below $\sigma_{\mathrm{MCS}}$. (The experiment of the upper panel of Fig. 2 is represented by the last point on the right of $\mathrm{Fig.} \mathrm{7.)}$

Figures 6 and 7 represent a step size $c$ of 10 , or, in units of $\sigma_{\mathrm{MCs}}, \mathrm{c}^{\prime}=1.0$. Calculations similar to those

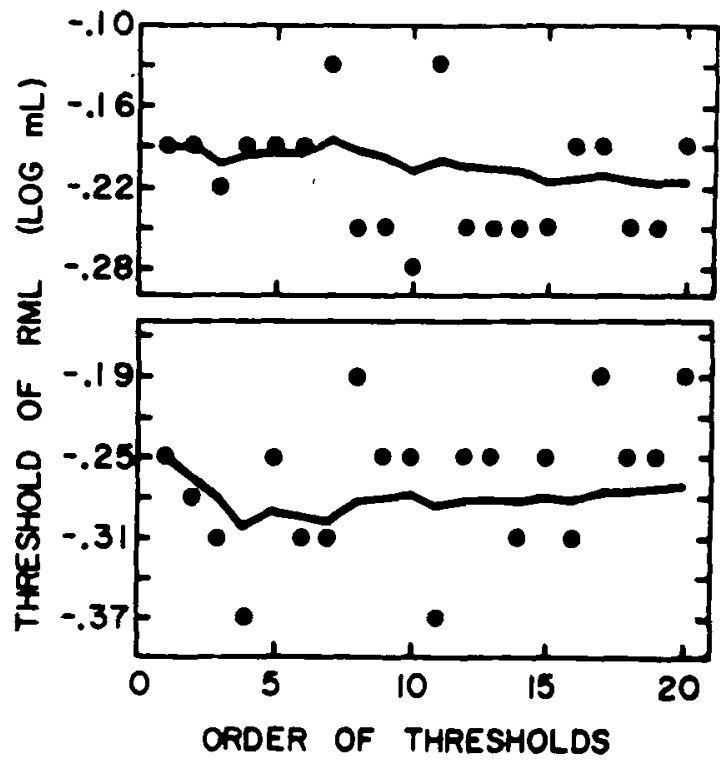

Fig. 5. Order of occurrence of 20 successive thresholds. The line in each panel represents the mean threshold based on the given number of thresholds, that is, the "running mean." O A.L.: upper panel, Session 1 : lower panel, Session 2. 


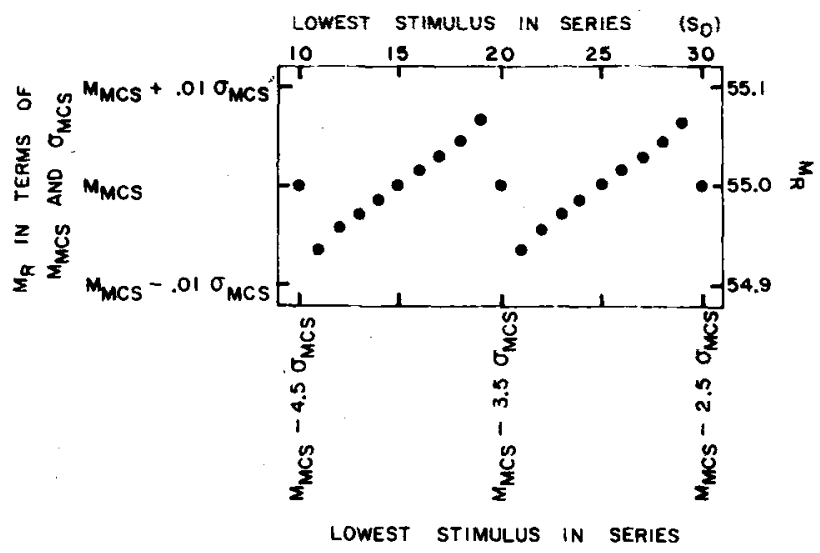

Fig. 6. Mean thresholds of RML threshold distributions as a function of the lowest stimulus, $S_{0}$, used. Step size $c=\sigma_{\mathrm{MCS}}$. Upper and right scales refer to numerical example. Lower and left scales refer to general case.

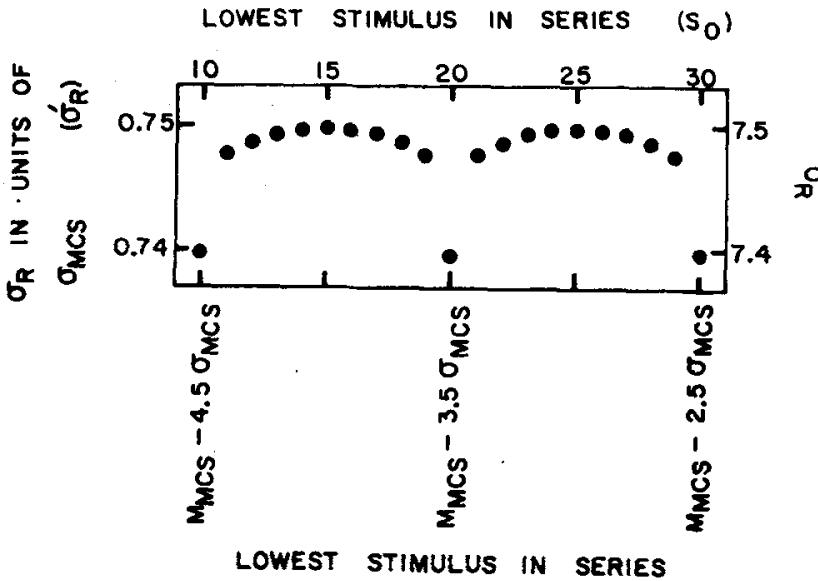

Fig. 7. Standard deviations of RML threshold distributions as a function of the lowest stimulus, $S_{0}$, used. Step size $c=\sigma_{M C S}$. Upper and right scales refer to numerical example. Lower and left scales refer to general case.

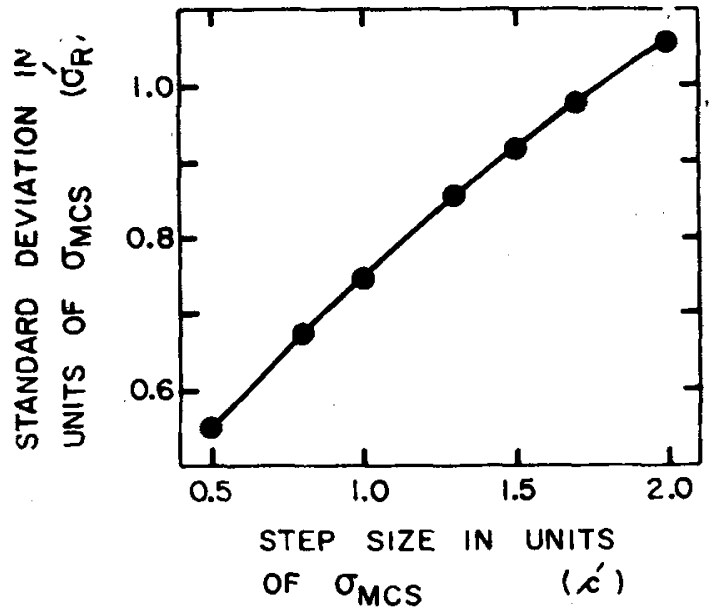

Fig. 8. Standard deviation of RML threshold distributions as a function of step size. required for Figs. 6 and 7 were made for $\mathrm{c}^{\prime}=0.5,0.8$, $1.0,1.3,1.5,1.7$, and 2.0. The calculations indicated that, for different values of $S_{0}$ and $c^{\prime}$, to a very close approximation

$$
\mathrm{M}_{\mathrm{R}}=\mathrm{M}_{\mathrm{MCs}} .
$$

As step size $\mathbf{c}^{\prime}$ increases, the closeness of the approximation of Eq. 8 becomes poorer. However, even with the largest step size, namely $c^{\prime}=2.0$, the greatest difference between $M_{R}$ and $M_{M C s}$ is still very small, the maximum difference being equal to $.0166 \sigma_{\mathrm{MCs}}$. This means, in terms of the numerical example (see Fig. 6), that in the worst possible case $\mathbf{M}_{\mathbf{R}}$ could only be as low as 54.834 or as high as 55.166 .

The calculations also indicated that $\sigma_{\mathrm{R}}^{\prime}$ varied very little for a given $\mathrm{c}^{\prime}$, as in Fig. 7. For different $\mathrm{c}^{\prime}$ values, however, the value of $\sigma_{R}^{\prime}$ varied. For each $c^{\prime}$ value, for different $S_{0}$ values, the median $\sigma_{R}^{\prime}$ was determined. For $c^{\prime}=1.0$, for example, the median $\sigma_{\mathrm{R}}^{\prime}$ was 0.7489 (see Fig. 7). A plot of median $\sigma_{\mathbf{R}}^{\prime}$ as a function of $c^{\prime}$ is given in Fig. 8. The least-squares equation derived to describe the relationship is

$$
\sigma_{\mathrm{R}}^{\prime}=.3188+.4892 \mathrm{c}^{\prime}-.0602 \mathrm{c}^{\prime 2},
$$

and the curve in Fig. 8 is a plot of this equation.

Substituting, in Eq. 9, $\sigma_{\mathrm{R}} / \sigma_{\mathrm{M}} \mathrm{cs}$ for $\sigma_{\mathrm{R}}^{\prime}$ and $\mathrm{c} / \sigma_{\mathrm{MCs}}$ for $c^{\prime}$, simplifying, and solving for $\sigma_{M}$ Cs gives

$$
\sigma_{\mathrm{MCS}}=\frac{\left(\sigma_{R}-.4892 \mathrm{c}\right)+\sqrt{\left(\sigma_{R}-.4892 \mathrm{c}\right)^{2}+.0768 \mathrm{c}^{2}}}{.6376} \text {. }
$$

\section{APPENDIX B}

Derivation of Equation for the Standard Error of the Mean Threshold of the Random Method of Limits

The threshold distributions of Fig. 2 represent expectations based on an infinitely large number of thresholds. But any psychophysical experiment represents a limited number of thresholds. For a finite number of thresholds, an estimate of the accuracy of $M_{R}$ is given by the standard enror of $M_{R}$ :

$$
S E_{M_{R}}=\sigma_{R} / T^{1 / 2},
$$

where $T$ is the number of thresholds. The relationship of Fig. 8 indicates that a smaller step size yields a smaller $\sigma_{\mathbf{R}}^{\prime}$ and thus, for the same number of thresholds, yields a smaller $\mathbf{S E}_{\mathbf{M}_{\mathbf{R}}}$. A small step size, however, requires more judgments per threshold than does a large step size. Thus, the more pertinent question is: for a given number of judgments, what step size gives the smallest ${ } E_{M_{R}}$ ?

The number of thresholds obtained in a RML experiment depends upon the number of judgments $(\mathrm{J})$ made, and the number of judgments required per threshold $(J / T)$. Specifically, $J /(J / T)=T$. Substituting $\mathrm{J} /(\mathrm{J} / \mathrm{T})$ for $\mathrm{T}$ in $\mathrm{Eq} .11$ gives

$$
\mathrm{SE}_{\mathbf{M}_{\mathbf{R}}}=\sigma_{\mathbf{R}}(\mathrm{J} / \mathrm{T})^{1 / 2} / \mathrm{J}^{1 / 2},
$$


or

$$
\mathrm{SE}_{\mathrm{M}_{\mathrm{R}}}^{\prime}=\sigma_{\mathbf{R}}^{\prime}(\mathrm{J} / \mathrm{T})^{3 / 2} / \mathrm{J}^{2 / / 4},
$$

where $\mathrm{SE}_{\mathbf{M}_{\mathbf{R}}}^{\prime}=\mathrm{SE}_{\mathrm{M}_{\mathbf{R}}} / \sigma_{\mathrm{MCs}}$ and $\sigma_{\mathrm{R}}^{\prime}=\sigma_{\mathbf{R}} / \sigma_{\mathrm{Mcs}}$.

The question to be considered is how $\sigma_{R}^{\prime}(\mathrm{J} / \mathrm{T})^{1 / 2}$ of Eq. 13 varies as both step size, $c^{\prime}$, and the lowest stimulus, $S_{0}$, vary. Figure 9 provides some sample data indicating how $\sigma_{\mathbf{R}}^{\prime}(\mathrm{J} / \mathrm{T})^{1 / 2}$ varies for different step sizes and for different $S_{0}$ values, with $S_{0}$ varying from $\left(\mathrm{M}_{\mathrm{MCS}}-3.5 \sigma_{\mathrm{MCS}}\right)$ to $\left(\mathrm{M}_{\mathrm{MCS}}-2.5 \sigma_{\mathrm{MCS}}\right)$. For example, the lowest point on the extreme right of Fig. 9 represents the case depicted in the upper panel of Fig. 2; $\mathrm{S}_{0}=\mathrm{M}_{\mathrm{Mcs}}-2.5 \sigma_{\mathrm{Mcs}}, \mathrm{c}^{\prime}=1.0, \sigma_{\mathrm{R}}^{\prime}=.7397, \mathrm{~J} / \mathrm{T}=6$, and $\sigma_{\mathbf{R}}^{\prime}(\mathrm{J} / \mathrm{T})^{1 / 2}=1.8119 .6$ From curves like those of Fig. 9, for each step size, $c^{\prime}$, the median value of $\sigma_{\mathbf{R}}^{\prime}(\mathrm{J} / \mathrm{T})^{\mathrm{t} / \mathrm{z}}$ was calculated. These medians are presented in Fig. 10. As indicated by Figs. 9 and 10, variation in step size between $c^{\prime}=.5$ to $c^{\prime}=2.0$, along with variation in $S_{0}$ between $\left(M_{M C s}-3.5 \sigma_{M C s}\right)$ and $\left(\mathrm{M}_{\mathrm{MCS}}-2.5 \sigma_{\mathrm{MCS}}\right)$, have relatively little influence upon $\sigma_{\mathbf{R}}^{\prime}(\mathrm{J} / \mathrm{T})^{1 / 2}$. Taking the median value of Fig. 10, namely 2.05 , as representative of all, and inserting this in place of $\sigma_{R}^{\prime}(J / T)^{1 / 2}$ in Eq. 13 gives

$$
\mathrm{SE}_{\mathrm{M}_{\mathbf{R}}}^{\prime}=2.05 / \mathrm{J}^{1 / 2}
$$

and substituting $S E_{M_{\mathbf{R}}} / \sigma_{M_{\mathbf{M}} \mathrm{S}}$ for $\mathrm{SE}_{\mathbf{M}_{\mathbf{R}}}^{\prime}$ in Eq. 14 gives

$$
\mathrm{SE}_{\mathrm{M}_{\mathrm{R}}}=2.05 \sigma_{\mathrm{MCS}} / \mathrm{J}^{1 / 2} \text {. }
$$

The value of $\sigma_{\mathrm{MCs}}$ used in Eq. 15 may be obtained by Eq. 10.

\section{REFERENCES}

Guilford, J. P. Psychometric methods. (2nd ed.) New York: McGraw-Hill, 1954.

Herrick, R. M. Psychophysical methodology: Comparison of thresholds of the method of limits and of the method of constant stimuli. Perceptual \& Motor Skills, 1967, 24, 915-922.

Herrick, R. M. Psychophysical methodology: Deductions from the phi-gamma hypothesis and related hypotheses. Perception \& Psychophysics, 1970a, 7, 73-78.

Herrick, R. M. Psychophysical methodology: IV. Phi gamma hypothesis and the method of limits. Perception \& Psychophysics, 1970b, 8, 61-64.

Herrick, R. M. Accuracy of the mean threshold in the psychophysical method of limits. Naval Air Development Center Report 72064-CS, 1972a.

Herrick, R. M. Increment thresholds for two identical flashes. Journal of the Optical Society of America, 1972b, 62, 104-110.

Herrick, R. M., \& Thiesen, C. J., Jr. Increment thresholds for two nonidentical flashes. Journal of the Optical Society of America, 1972, 62, 588-593.

Holt, E. B. The classification of psycho-physic methods. Psychological Review, 1904, XI, 343-369.

Titchener, E. B. Experimental psychology: Vol. II, Part II. New York: Macmillan, 1905.

Urban, F. M. On the method of just perceptible differences. Psychological Review, 1907, 14, 244-253.

Urban. F. M. The application of statistical methods to the problems of psychophysics. Philadelphia: Psychological Clinic Press, 1908.

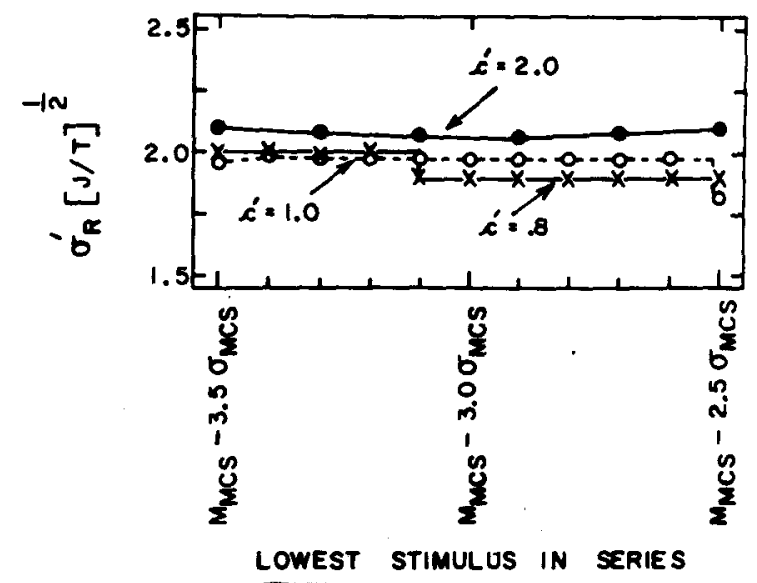

Fig. 9. The quantity $\sigma_{R}^{\prime}(J / T)^{1 / 2}$ as a function of the lowest stimulus, $S_{0}$, used for different step sizes, $c^{\prime}$.

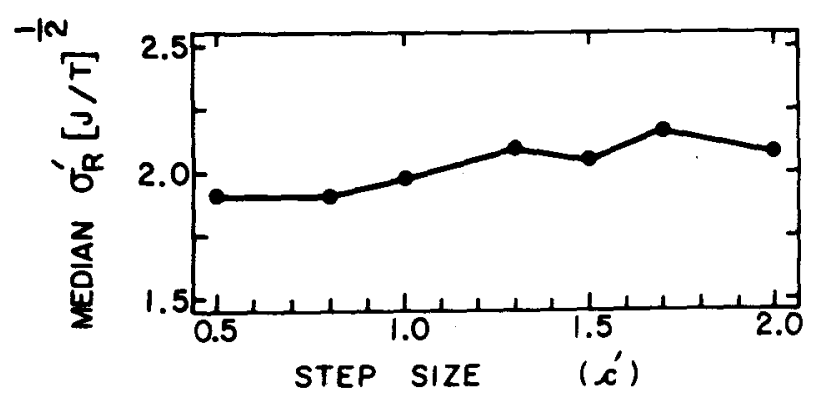

Fig. 10. Median $\sigma_{\mathbf{R}}^{\prime}(\mathrm{J} / \mathrm{T})^{1 / 2}$ as a function of step size. $c^{\prime}$.

\section{NOTES}

1. The calculation for the ascending (and descending) estimate in Table 1 follows the standard procedure for computation in the ascending (and descending) method of limits (see Herrick. 1967). In the RML, a mathematically equivalent computation is to take the highest stimulus at which a "no" occurred as the ascending estimate, and the lowest stimulus at which a "yes" occurred as the descending estimate.

2. The analysis given here is for the phi-gamma hypothesis. Following the same steps, the interested reader may perform similar analyses on the assumption of the log phi-gamma hypothesis, the quantal hypothesis, or any other hypothesis.

3. In this numerical example, and in the analyses that follow, $\mathrm{p}$ values at and below $2.5 \mathrm{\sigma}$ below the mean are taken as 0.00 , and $\mathrm{p}$ values at and above $2.5 \sigma$ above the mean are taken as 1.00 (see Fig. 1).

4. Thanks to A. W. Lewis for performing most of the calculations required in the analyses, and for serving as an $O$ and as an $\mathrm{E}$.

5. When the stimuli are selected with respect to the axis of symmetry of the psychometric function, $M_{R}$ is exactly equal to

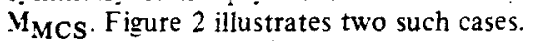

6. With $\mathrm{c}^{\prime}=1.0, \sigma_{\mathbf{R}}^{\prime}$ is the same for $\mathrm{S}_{0}=\mathrm{M}_{\mathrm{MCS}}-2.5 \sigma_{\mathrm{MCS}}$ and for $S_{0}=\mathrm{I}_{\mathrm{MCS}}-3.5 \sigma_{\mathrm{MCS}}$, as shown in Fig. 7 . In the former case, $J / T$ is 6 ; in the latter, $J / T$ is 7 . Thus, $\sigma_{R}^{\prime}(J / T)^{1 / 2}$ differs slightly for the two cases.

(Received for publication September 27, 1972; revision received February 21. 1973.) 